\title{
Graduated drivers' licences for seniors: reclaiming one benefit of being young
}

\author{
Donald A. Redelmeier MD MSHSR, Matthew B. Stanbrook MD PhD
}

$\mathrm{M}$ any will reach a point in life where they become unable to operate heavy machinery safely. Cars are the ubiquitous example. Some seniors remain excellent drivers, but others accumulate medical comorbidities, cognitive impairments or physical frailties that can make them a hazard to themselves and other road users. Of the 2209 Canadians who died in motor vehicle accidents in 2009, 389 were over age 65, a higher incidence than any other age group and far higher than those half their age. ${ }^{1}$ For every death, an additional 35 individuals were injured. ${ }^{1}$

The relation between advanced age and driving risk is complex and influenced by individual contributing factors, as Hauer thoughtfully argues in his commentary in $C M A J .{ }^{2} \mathrm{Nev}-$ ertheless, some seniors keep driving despite substantial physical or mental deterioration that makes them medically unfit to drive. For example, about one in four Canadians over 65 with dementia retain a driver's licence, and about one in five continue to drive regularly. ${ }^{3}$ Such statistics have aroused public concerns and prompted government action because dangerous driving imposes risks on others. ${ }^{4}$

Frail patients in past decades often relinquished driving because the physical demands were exhausting. In contrast, new advances in vehicle technology (e.g., power steering, power brakes, power seats) have made driving increasingly popular among those who may be increasingly less capable.

Mandatory road testing, physician-based screening and other proposed solutions to this problem have proved controversial in terms of accuracy, fairness, feasibility, affordability or adherence. In the interim, restriction of licences throughout Canada generally occurs only after accumulation of moving violations. This approach is often too late to prevent injuries. Pre-emptive approaches based on reporting of medically unfit drivers by physicians is a more proactive approach, yet is marked by low adherence even when such reporting is mandatory. ${ }^{5}$

A look at the other end of the age spectrum might offer a better solution. Graduated licensing programs for young drivers have shown surprising effectiveness for preventing motor vehicle crashes. ${ }^{6}$ Typical restrictions disallow driving at night, on high-speed roads or with any blood alcohol concentration. The result has been a $20 \%-40 \%$ reduction in serious road trauma in this age group, which in Canada amounts to preventing about 100 teen deaths each year.

The compelling benefits to young drivers suggest that a policy of graduated licensing for seniors also deserves serious consideration. With this approach, a full driver's licence defaults automatically to a restricted licence that allows seniors to continue to drive only under relatively favourable road conditions. Just like graduated licences for young drivers, the principle is to prevent trauma rather than to await a series of incidents before taking any action. The optimal transition time would be debatable, but might be based on a specific age, retirement or other benchmarks.

Graduated licensing must allow exemptions for seniors who show good health as certified by their physician. This reframes the interaction by placing the physician in a positive position of endorsing a full driver's licence, rather than always being in the negative position of initiating a restricted licence. This approach is logically no different from existing procedures whereby physicians certify eligibility for a disabled parking permit. Physicians could inform their judgment by employing external tools (some of which are being actively studied currently) for fitness-to-drive determinations.

Placing the onus on patients to seek a medical exemption would likely be more effective than relying on others to start discussions about medical suspension. The existence of a restricted licence option might further alleviate the polarizing all-or-none approach that hampers the fulsome reporting of medically unfit drivers of all ages. Moreover, an opt-out rather than opt-in approach to licensing is congruent with existing safety policies for aviators, vaccination programs for children and commercial driver testing.

Graduated licences work to keep young drivers safe. Let's extend the same benefits to seniors.

\section{References}

1. Canadian motor vehicle traffic collision statistics: 2009. Ottawa (ON): Transport Canada; 2009. Available: www.tc.gc.ca/eng/roadsafety/tp-tp3322-2009-1173.htm (accessed 2012 Mar. 13).

2. Hauer E. In defence of older drivers. CMAJ 2012;184:E305-6.

3. Turcotte M. Profile of seniors' transportation habits. Ottawa (ON): Statistics Canada; 2012. Cat. no. 11-008-X.

4. Welsh M, Sher J. Ontario says tougher rules expected for drivers with dementia. The Toronto Star. 2012 Feb. 21. Available: www.thestar.com/news/canada/politics/article /1134253--ontario-says-tougher-rules-expected-for-drivers-with-dementia (accessed 2012 Mar. 12).

5. Redelmeier DA, Venkatesh V, Stanbrook MB. Mandatory reporting by physicians of patients potentially unfit to drive. Open Med 2008;2:e8-17.

6. Shope JT. Graduated driver licensing: review of evaluation results since 2002. J Safety Res 2007;38:165-75.

Competing interests: None declared by Donald Redelmeier. See www.cmaj .ca/site/misc/cmaj_staff.xhtml for Matthew Stanbrook.

Affiliations: Donald Redelmeier is a professor of medicine with the University of Toronto, Toronto, Ont. Matthew Stanbrook is Deputy Editor, Research, CMAJ.

Correspondence to: CMAJ editor, pubs@cmaj.ca

CMAJ 2012. DOI:10.1503/cmaj.120521 